\title{
Thickness of the human cranial diploe in relation to age, sex and general body build
} Niels Lynnerup*†, Jacob G Astrup ${ }^{\dagger}$ and Birgitte Sejrsen ${ }^{\dagger}$

\author{
Address: Laboratory of Biological Anthropology, Institute of Forensic Medicine, University of Copenhagen, Denmark \\ Email: Niels Lynnerup* - n.lynnerup@antrolab.ku.dk; Jacob G Astrup - jacobastrup@dadlnet.dk; Birgitte Sejrsen - bs@forensic.ku.dk \\ * Corresponding author †Equal contributors
}

Published: 20 December 2005

Head \& Face Medicine 2005, I:13 doi:10.1 186/1746-160X-I-13

This article is available from: http://www.head-face-med.com/content/I/I/I3

(C) 2005 Lynnerup et al; licensee BioMed Central Ltd.

This is an Open Access article distributed under the terms of the Creative Commons Attribution License (http://creativecommons.org/licenses/by/2.0), which permits unrestricted use, distribution, and reproduction in any medium, provided the original work is properly cited.
Received: 25 October 2005

Accepted: 20 December 2005

\begin{abstract}
Background: Earlier studies have addressed the human total cranial vault thickness and generally found no correlation with sex, age or body weight. However, the thickness of the diploe has not been investigated. Our study has determined the diploeic thickness of the human cranial vault using modern autopsy material.
\end{abstract}

Methods: The diploeic bone thickness was measured in 64 individuals (43 males, 21 females) autopsied at our institute. The thickness was measured by X-raying biopsies trephined at four specific locations on the skull. Complete medical records and pathologic autopsy results were available.

Results: There was a statistically significant difference in diploeic thickness between males and females in the frontal region only. Diploeic thickness was highly correlated with total cranial vault bone thickness, except for the left euryon in females. Subsequent analyses failed to reveal any correlations between the diploeic thickness and age and height and weight of the individual.

Conclusion: Males overall have a thicker diploe, albeit this difference is statistically significant only in the frontal region. We could not discern any trends as pertains to diploeic thickness versus age, height or weight. Since the thickness of the diploe may be an important parameter in biomechanical modelling of the cranial vault, this means that the diploe can be built into such models based on the total cranial thickness, except for the frontal region where the sexual dimorphism must be taken into account. Our findings are consistent with previous studies relating the total cranial thickness to the same parameters, in that we found a high correlation between diploeic and total cranial thickness (except at the left euryon for females). Finally, we recommend that future studies try to incorporate CT or MR scan imaging, rather than point sampling, in order to achieve a total assessment of the dimensionalities of the diploe.

\section{Background}

While the thickness of the human cranial vault has been investigated before, not least in terms of the relationship between cranial thickness and sex, age and general body build [1-11], these studies have mostly addressed the total thickness (diploe and the external and internal table). The main incentive for those studies has been to determine whether cranial vault thickness could be used as an indicator of sex and age. However, no clear trends have emerged, and the results have been somewhat conflicting. 


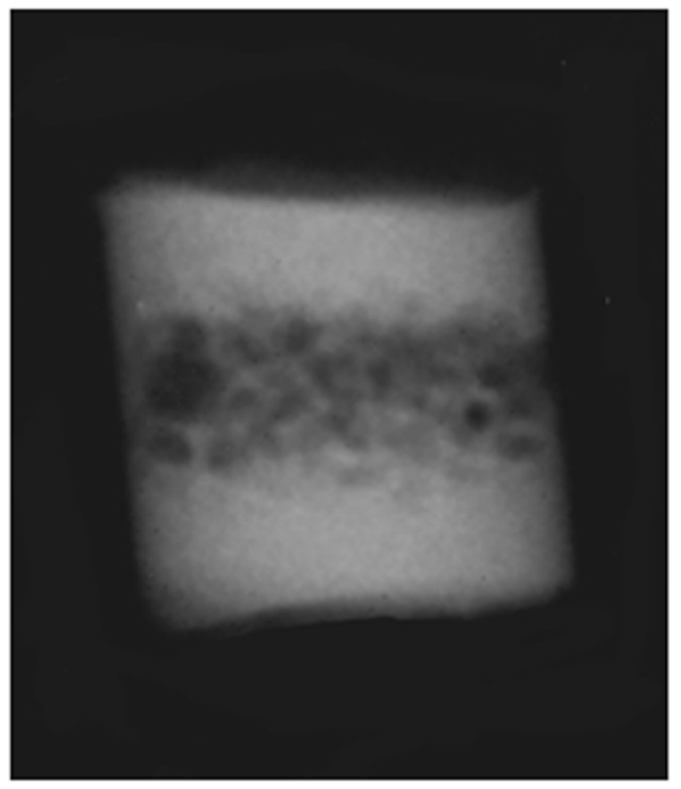

\section{External table (compact bone) Diploe (trabecular or spongy bone) Internal table (compact bone)}

Figure I

X-ray of a biopsy. The three bone layers of the cranial vault are indicated.

We wanted to analyse whether trends useful for sexing and ageing might emerge if we focused on the diploe (the cancellous or spongy bone within the laminae, or tables, of the vault bones of the skull [12] (see figure 1)). A few other studies have addressed the diploeic thickness, but these studies have mainly dealt with issues of cranial reconstructive surgery $[13,14]$.

Diploeic and cranial thickness is an important variable to consider when carrying out biomechanical modelling of the skull. This has become an interesting venue of research, e.g. in terms of modelling cranial fractures in forensic pathology [15], and more detailed material properties of the human skull lately been presented, including the cross-sectional proportions of compact and cancellous bone $[16,17]$.
We used X-rays to visualise the bone components. We used the same samples as in a previous study: a modern forensic material with complete autopsy results and antemortem medical information [11]. This also allowed us to compare the measures taken physically of the bone samples in the previous study with the measures taken from analyses of the X-rays.

While the external cranial surface is overall fairly smooth (at least above the linea nuchae and temporal-masseter line), the internal surface is much more irregular. This will of course have implications for measurements taken directly with calipers on cut margins, or on trephined specimens or when measuring thickness on cranial X-rays. Cranial thickness has been measured by X-rays in numerous studies, but often employing indirect projections or

Table I: Summary statistics and significance tests (Mann-Whitney) for diploeic thickness measures by sex.

\begin{tabular}{|c|c|c|c|c|c|c|}
\hline Sampling point & $\mathrm{n}$ & Mean $(\mathrm{mm})$ & Std. Dev. (mm) & Range (mm) & $U$ & $P$ \\
\hline Frontal Male & 41 & 2.954 & 1.135 & $1.000-7.000$ & 212.00 & 0.001 \\
\hline Female & 21 & 2.019 & 0.966 & $0.000-4.300$ & & \\
\hline Occipital Male & 37 & 3.573 & 1.462 & $0.800-7.800$ & 267.00 & 0.236 \\
\hline Female & 18 & 2.972 & 1.476 & $0.000-5.600$ & & \\
\hline Right euryon Male & 42 & 1.838 & 1.128 & $0.000-4.500$ & 401.00 & 0.968 \\
\hline Female & 18 & 1.961 & 1.123 & $0.000-4.700$ & & \\
\hline Left euryon Male & 41 & 1.724 & 1.162 & $0.000-4.900$ & 392.00 & 0.710 \\
\hline Female & 19 & 1.537 & 1.008 & $0.000-3.600$ & & \\
\hline
\end{tabular}




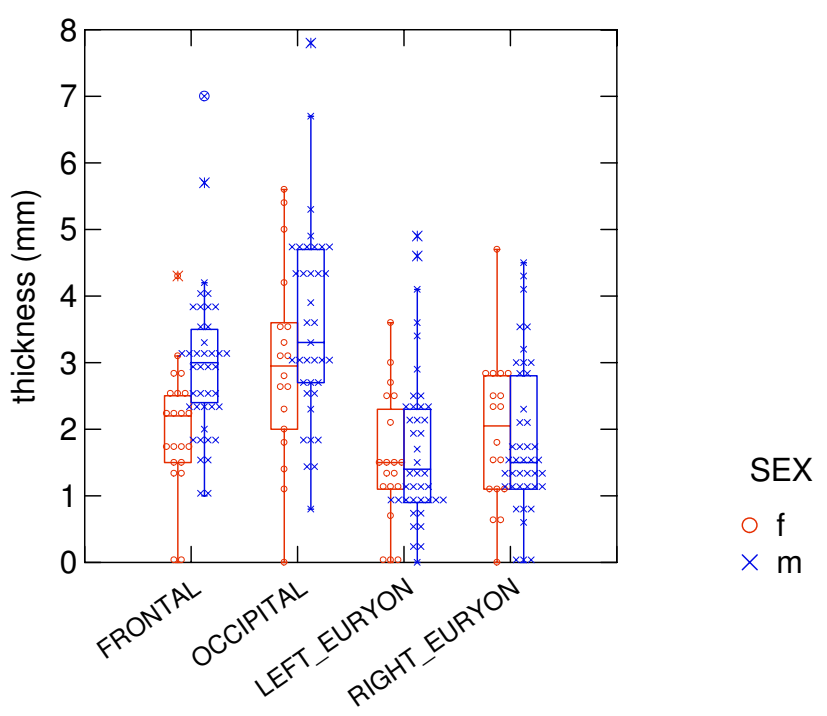

Figure 2

Plot showing values for diploeic thickness at the four sampling points. F:frontal; O: occipital; R: right euryon; and L: left euryon ( $0=$ females, $x=$ males $)$.

just using lateral projections [3,18-22]. There is probably no way to rigorously standardize cranial thickness measurements. However, we feel that our method of X-raying trephined bone biopsies is superior to analyses of, e.g., lateral cranial X-rays, as the bone structures are visualised in a perpendicular view without juxtapositional structures (see figure 1).

\section{Methods}

The biopsies were obtained from 64 autopsied individuals at the Institute of Forensic Medicine, University of Copenhagen. The material consisted of cranial vault bone biopsies from 43 males (age range: $16-90$, mean \pm 1 S.D. $=48$ \pm 17 years) and 21 females (age range: $23-84$ years, mean \pm 1 S.D. $=48 \pm 16$ years). The biopsies were taken sequentially over a 6 month period, although selection by age was made to ensure a reasonable spread in age over adult ages. Cases with cranial trauma were excluded due to the forensic pathological exigencies of these cases.
The cranial vault biopsies were taken from four sites on each individual: (1) $1 \mathrm{~cm}$ in front of the bregma; (2) $1 \mathrm{~cm}$ behind lambda; (3) left euryon and (4) right euryon. Determination of the euryon sampling points was made visually. The biopsies were made with a $5 \mathrm{~mm}$ trephine perpendicular to the outer plane. The specimens were stored in coded, separate containers in $97 \%$ alcohol. In our previous study [11] the thickness of each specimen had been measured without knowledge of sex or age using a digital caliper connected to a computer [23]. In this study the specimens were X-rayed using a Siemens Dentotime ${ }^{\circledR}$ equipped with a Heliodent 70 tubus (exposure settings: $70 \mathrm{kV}$ and $7 \mathrm{~mA}$ ). A coin, precisely $10 \mathrm{~mm}$ in diameter, was placed alongside the single biopsy for calibration purposes. The X-rays were analysed using the software associated with the digital X-ray equipment (VixWin32 by Gendex Imaging ${ }^{\circledR}$ ). The software allowed for image calibration and morphometric analyses, whereby we measured the thickness of the diploe; the compact bone of the inner and outer plate; and total cranial thickness (figure 1). All measures were made without knowledge of sex or age. As a control, we compared our previous results (total cranial thickness measured with a calliper) with the present data (total cranial thickness measured on digital X-ray).

Autopsy finds and ante-mortem medical data were available, indicating that 27 cases had a history of, and autopsy finds consistent with, chronic drug and alcohol abuse. There were no cases with recognized bone or craniofacial diseases. Height and weight of the individuals was also recorded.

Mann-Whitney test was used to analyze for betweengroup differences and Pearson correlation tests were used to analyze correlations between diploeic thickness measures, age, height and weight. Scatterplots with LOWESS smoothing were used for graphical analyses of trends in cranial diploeic thickness vs. sex $[10,24]$.

\section{Results}

There were no statistically significant differences between the age makeup of the male and female subsamples ( $\mathrm{p}=$ $0.937)$. There were no statistically significant differences in the thickness measures (including both total thickness

Table 2: Pearson correlation matrix for diploeic thickness for males. Probabilities are Bonferroni adjusted probabilities.

\begin{tabular}{|c|c|c|c|c|c|c|c|c|}
\hline \multirow[b]{2}{*}{ Frontal } & \multicolumn{2}{|c|}{$\begin{array}{c}\text { Frontal } \\
\text { corr. Coef. } \mathrm{P}\end{array}$} & \multicolumn{2}{|c|}{$\begin{array}{c}\text { Occipital } \\
\text { corr. coef. P }\end{array}$} & \multicolumn{2}{|c|}{$\begin{array}{l}\text { Right euryon } \\
\text { corr. coef. } \mathrm{P}\end{array}$} & \multicolumn{2}{|c|}{$\begin{array}{l}\text { Left euryon } \\
\text { corr. coef. p }\end{array}$} \\
\hline & 1.000 & 0.0 & & & & & & \\
\hline Occipital & 0.473 & 0.028 & 1.000 & 0.0 & & & & \\
\hline Right eu & 0.312 & 0.433 & 0.138 & 1.000 & 1.000 & 0.0 & & \\
\hline Left eu & 0.324 & 0.370 & 0.177 & 1.000 & 0.712 & 0.000 & 1.000 & 0.0 \\
\hline
\end{tabular}


Table 3: Pearson correlation matrix for diploeic thickness for females. Probabilities are Bonferroni adjusted probabilities.

\begin{tabular}{|c|c|c|c|c|c|c|c|c|}
\hline \multirow[b]{2}{*}{ Frontal } & \multicolumn{2}{|c|}{$\begin{array}{c}\text { Frontal } \\
\text { corr. Coef. P }\end{array}$} & \multicolumn{2}{|c|}{$\begin{array}{c}\text { Occipital } \\
\text { corr. coef. P }\end{array}$} & \multicolumn{2}{|c|}{$\begin{array}{l}\text { Right euryon } \\
\text { corr. coef. P }\end{array}$} & \multicolumn{2}{|c|}{$\begin{array}{l}\text { Left euryon } \\
\text { corr. coef. } \mathrm{P}\end{array}$} \\
\hline & 1.000 & 0.0 & & & & & & \\
\hline Occipital & 0.352 & 1.000 & 1.000 & 0.0 & & & & \\
\hline Right eu & 0.336 & 1.000 & 0.137 & 1.000 & 1.000 & 0.0 & & \\
\hline Left eu & -0.113 & 1.000 & -0.017 & 1.000 & 0.628 & 0.055 & 1.000 & 0.0 \\
\hline
\end{tabular}

and diploeic thickness) between the 27 cases with a history of chronic drug and alcohol abuse (19 males and 8 females) and the cases without such a history (24 males and 13 females). Consequently, all cases were used in the subsequent analyses.

Delineation between the compact bone and cancellous bone was not possible in 19 single biopsies ( 9 occipital; 2 frontal; 4 left and 4 right euryon, out of a total of 256 biopsies). When we compared the total cranial thickness as determined in our previous study [11] with the present and we found (expected) high correlations for all four sites (Pearson correlation coefficients: Frontal: $r=0.972$; Occipital: $r=0.971$; Right euryon: $r=0.920$; and Left euryon: $r=0.962$ ).

We found no statistically significant differences between males and females for the diploeic thickness, except for the frontal biopsies where there was a statistically significant difference with males having the thickest measures (table 1 and figure 2). It may be noted that males overall had the thickest diploeic bone layer also occipitally and at the left euryon, albeit not statistically significant.

Tables 2 and 3 show the Pearson correlation matrices for the correlation between the diploeic thicknesses at the four sample points by sex. For males there is both a significant correlation between frontal and occipital thickness $(p=0.028)$, as well as between the left and right euryon $(\mathrm{p}<0.001)$. The latter is barely the case for females $(\mathrm{p}=$ $0.055)$.

Table 4: Pearson correlations for diploeic and total cranial thickness.

\begin{tabular}{lcccc}
\hline & \multicolumn{2}{c}{ Males } & \multicolumn{2}{c}{ Females } \\
\hline & $r$ & $P$ & $r$ & $P$ \\
\hline Frontal dip. vs. total & 0.759 & 0.000 & 0.729 & 0.038 \\
Occipital dip. vs. total & 0.584 & 0.008 & 0.771 & 0.013 \\
Right euryon dip. vs. total & 0.915 & 0.000 & 0.845 & 0.001 \\
Left euryon dip. vs. total & 0.871 & 0.000 & 0.451 & 1.000 \\
\hline
\end{tabular}

The thickness of the diploe was highly correlated with total cranial thickness at all sampling points, except at the left for females (table 4).

There was no correlation between diploeic bone layer thickness and age, height or weight (table 5). Finally, LOWESS-smoothed scatter plots were produced of the four measures by age by sex (figures 3, 4, 5, 6). The plots did show a slight trend for increase in diploeic bone thickness at the left and right euryon (figures 5 and 6) for both males and females. However, the increase is first apparent above approximately 60 years of age and there is a high degree of variation when looking at the single datapoints.

\section{Discussion}

We have earlier investigated total cranial vault thickness in relation to age, height and weight in a Danish forensic sample [11]. We did not then find any statistically significant correlations at the four sampling points (frontal, occipital and left and right euryon) with sex. However, that study was made by direct measurement on trephined

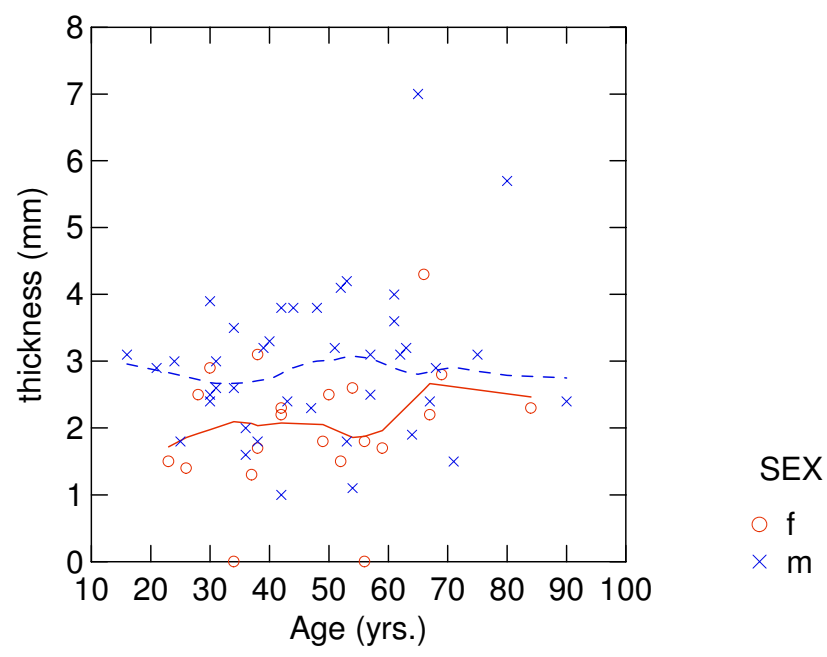

Figure 3

Scatter plot showing frontal diploeic thickness against age (o $=$ females, $x=$ males) with LOWESS smoothing (unbroken line = females; broken line $=$ males). 
Table 5: Pearson correlation coeficients and associated probabilities between diploeic thickness and age, height and weight. Correlation tests were performed individually for each sampling point.

\begin{tabular}{|c|c|c|c|c|c|c|}
\hline \multirow[b]{2}{*}{ Frontal males } & \multicolumn{2}{|c|}{$\begin{array}{c}\text { Age } \\
\text { corr. coef. P }\end{array}$} & \multicolumn{2}{|c|}{$\begin{array}{c}\text { Height } \\
\text { corr. coef. } \mathrm{P}\end{array}$} & \multicolumn{2}{|c|}{$\begin{array}{c}\text { Weight } \\
\text { corr. coef. P }\end{array}$} \\
\hline & 0.207 & 1.000 & -0.172 & 1.000 & -0.062 & 1.000 \\
\hline females & 0.254 & 1.000 & 0.187 & 1.000 & 0.270 & 1.000 \\
\hline Occipital males & 0.293 & 0.470 & -0.280 & 0.556 & -0.132 & 1.000 \\
\hline females & 0.398 & 0.610 & -0.107 & 1.000 & -0.209 & 1.000 \\
\hline Right euryon males & 0.062 & 1.000 & -0.062 & 1.000 & -0.018 & 1.000 \\
\hline females & 0.265 & 1.000 & -0.222 & 1.000 & -0.221 & 1.000 \\
\hline Left euryon males & 0.117 & 1.000 & -0.030 & 1.000 & -0.082 & 1.000 \\
\hline females & 0.233 & 1.000 & -0.233 & 1.000 & -0.175 & 1.000 \\
\hline
\end{tabular}

samples, and we did not investigate the relationship between the compact bone layers and the diploe.

As in our previous study, the cranial biopsies were measured without any knowledge of the medical data of the deceased, and only the cases with cranial trauma were a priori excluded, due to the forensic pathological exigencies in these cases. When the medical data was accessed, there were no cases with diseases of the bone or bone metabolism. However, a large part of the material consisted of individuals with a known history of drug and alcohol abuse (also in several cases the direct cause of death). Chronic drug and alcohol abuse may derange bone metabolism [25] resulting in bone mass reduction $[26,27]$ and impairment of osteoblastic actitvity [28]. Moderate levels of consumption, on the other hand, seems to correlate positively with central and peripheral bone mineral density [25]. We found no statistically sig-

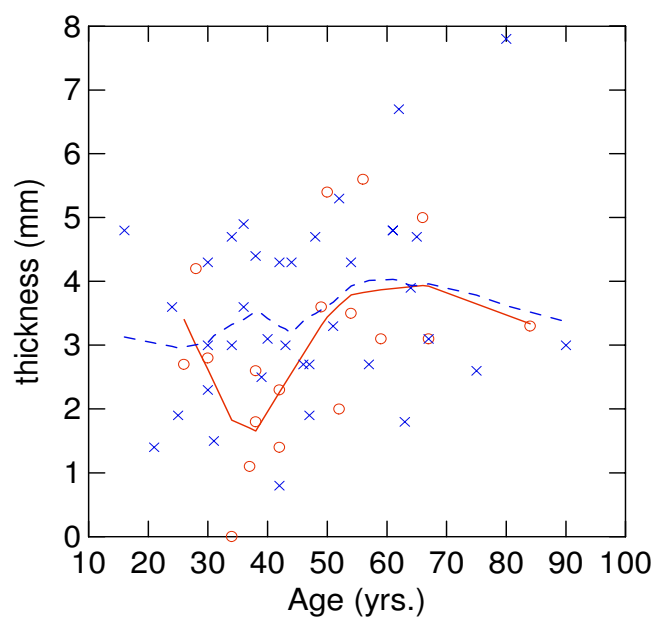

SEX

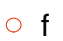

$\times \mathrm{m}$

\section{Figure 4}

Scatter plot showing occipital diploeic thickness against age ( $\mathrm{o}=$ females, $\mathrm{x}=$ males) with LOWESS smoothing (unbroken line $=$ females; broken line $=$ males $)$. nificant differences when comparing the data on the diploeic thickness from individuals with drug abuse with the rest of the material.

The diploeic thickness was difficult to measure on some biopsies (table 1), as the demarcation between the diploe (cancellous or spongy bone) and the compact bone of theexternal and internal table of the cranial vault was uncertain. The thickness could not be measured for 19 biopsies (as opposed to determining that there was no cancellous bone, which was the case with 10 samples). The 19 samples with undeterminable demarcation of the diploe were not distinct in terms of age and sex from the sample as a whole.

Our main finding was a statistically significant sexual dimorphism in diploeic thickness in the frontal region,

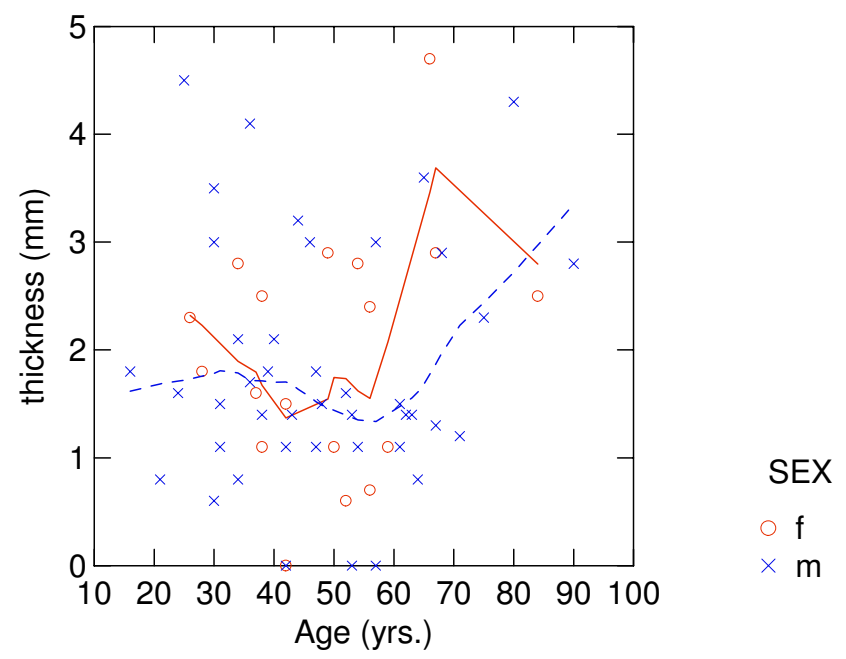

Figure 5

Scatter plot showing diploeic thickness at right euryon against age ( $0=$ females, $x=$ males $)$ with LOWESS smoothing (unbroken line $=$ females; broken line $=$ males). 


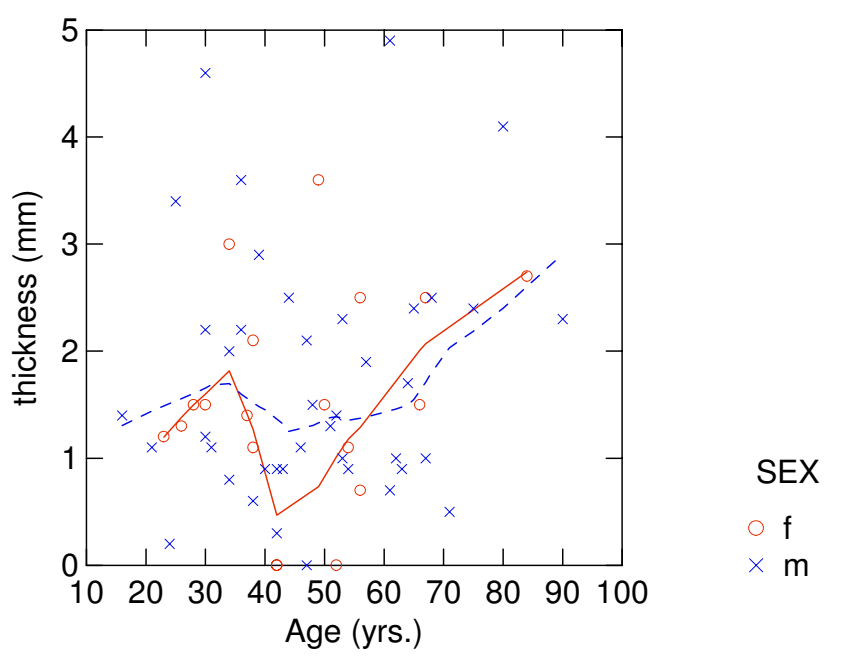

\section{Figure 6}

Scatter plot showing diploeic thickness at left euryon against age (o $=$ females, $x=$ males) with LOWESS smoothing

(unbroken line $=$ females; broken line $=$ males).

with males having a thicker diploe than females. The difference is though not directly applicable as a sex indicator, e.g., for the physical anthropologist dealing with human remains, due to the rather large overlap between males and females. The total bone thickness was not different as already determined in our previous study [11]. Males also had a thicker diploe in the occipital region and at the left euryon than female skulls, but these differences were not statistically significant. The thickness of the diploe was somewhat correlated between left and right euryon (statistically significantly so only for males), and between frontal and occipital sampling points for males. This indicates that no general statements may be made on the overall diploeic thickness of a skull.

Several authors have recorded a slight increase in cranial thickness with age and have related the frontal bone thickness increase to hyperostosis frontalis interna $[4,5,10,29]$, while other results, also showing age-related increase in thickness [20], were later ascribed to inconsistencies in the radiologic examination [21]. It is assumed that hyperostosis frontalis interna is caused by a prolonged oestrogen production in modern (20 th century) females [6,30]. Ross et al. [10] found a $10 \%$ frequency of hyperostosis frontalis in females, but this is not supported by our study. We found no statistically significant correlation between age and diploeic thickness, thus reflecting previous results concerning total cranial thickness [5,9-11]. The LOWESS plots generally seem to indicate more variation with age in the frontal and occipital region for both males and females, whereas there is a slight increase in diploeic thickness with age at the left and right euryon. Calculating an index of diploeic and total thickness did not show any age-related or sexual dimorphic trends.

\section{Conclusion}

Based on our studies we thus find that neither cranial diploeic thickness nor cranial total thickness is statistically significantly associated with the sex, weight or stature of an individuals. The diploeic bone thickness covaries with the total thickness. Powerfully built individuals may in fact have rather thin cranial vaults, whereas small, slightly built people may have thick skulls. Since the degree of cranial fracturing due to external force has been related to cranial thickness and bone structure (see e.g. Gurdjian et al. [31]), this may have implications in a forensic pathological setting, as well as in biomechanic modelling of the cranial vault $[32,33]$.

This study, as well as many of the previous studies in this area, relies on measuring single biopsies sampled at specific locations on the cranial vault. More data, and especially more complete data might be produced, if the dimensionalities of the diploe (thickness, total volume, etc.) was calculated from serial CT or MR scans.

\section{Competing interests}

The author(s) declare that they have no competing interests.

\section{Authors' contributions}

NL conceived the study and its design and produced the biopsies used in the study, performed the statistical analyses and wrote the manuscript drafts. JA performed all measurements and digital X-ray image acquisition and participated in the statistical analyses. BS set up the digital $\mathrm{X}$-ray acquisition as well as measurement calibration. All authors read and approved the final manuscript.

\section{Acknowledgements}

This study was approved by the Scientific Ethical Committee of Copenhagen, Denmark (Case \# 0I-27I/95).

\section{References}

I. Anderson RJ: Observations on the Thickness of the Human Skull. Dublin Journal of Medical Science 1882, 74:270-280.

2. Todd TW: Thickness of the male white cranium. Anatomical Record 1924, 27:245-256.

3. Getz B: Skull Thickness in the Frontal and Parietal Regions. Acta Morphologica Neerlonda-Scandinavica 1960, 3:221-228.

4. Angel $L$ : Skull vault thickness variation. American Journal of Physical Anthropology 197I, 35:272.

5. Schmitt HP, Saternus KS: Beiträge zur forensischen Osteologie. III. Zur Frage der Bestimmung des Individualalters an Hand der Dicke der Schädelkalotte. Zeitschrift für Rechtsmedizin 1973, 72:40-49.

6. Ross MD, Lee KA, Castle WM: Skull thickness of Black and White races. South African Medical Journal 1976, 50:635-638.

7. Einy S, Smith P, Becker A: On the measurement of cranial thickness at nasion on cephalographs. American Journal of Physical Anthropology 1984, 65:313-314.

8. Pensler J, McCarthy JG: The calvarial donor site: an anatomic study in cadavers. Plastic \& Reconstructive Surgery 1985, 75:648-65I. 
9. Ishida $H$, Dodo $Y$ : Cranial thickness of modern and neolithic populations in Japan. Human Biology 1990, 62:389-40I.

10. Ross AH, Jantz RL, McCormick WF: Cranial thickness in American females and males. Journal of Forensic Sciences 1998, 43:267-72

II. Lynnerup N: Cranial thickness in relation to age, sex and general body build in a Danish forensic sample. Forensic Science International 200I, I I 7:45-5I.

12. Standring S, Ed: Gray 's Anatomy. In The anatomical basis of clinical practice London: Elsevier Churchill - Livingstone; 2005.

13. Hwang K, Hollinger JO, Chung RS, Lee SI: Histomorphometry of parietal bones versus age and race. J Craniofac Surg 2000, I I:I7-23.

14. Jung YS, Kim HJ, Choi SW, Kang JW, Cha IH: Regional thickness of parietal bone in Korean adults. Int J Oral Maxillofac Surg 2003, 32:638-641.

15. Yoganadan N, Pintar FA: Biomechanics of temporo-parietal skull fracture. Clin Biomech (Bristol, Avon) 2004, 19:225-239.

16. Peterson J, Dechow PC: Material properties of the inner and outer cortical tables of the human parietal bone. Anat Rec 2002, 268:7-15.

17. Peterson J, Dechow PC: Material properties of the human cranial vault and zygoma. Anat Rec A Discov Mol Cell Evol Biol 2003, 274:785-797.

18. Hansman CF: Growth of interorbital distance and skull thickness as observed in roentgenographic measurements. Radiology 1966, 86:87-96.

19. Smith P, Wax Y, Becker A, Einy S: Diachronic Variation in Cranial Thickness of Near Eastern Populations. American Journal of Physical Anthropology 1985, 67:127-133.

20. Israel H: Age Factor and the Pattern of Change in Craniofacial Structures. American Journal of Physical Anthropology 1973, 39:III-128.

21. Tallgren N: Neurocranial morphology and aging - a longitudinal roentgen cephalometric study of adult Finnish women. American Journal of Physical Anthropology 1974, 41:285-294.

22. Adeloye A, Kattan K, Silverman F: Thickness of the normal skull in the American blacks and whites. American Journal of Physical Anthropology 1975, 43:23-30.

23. Lynnerup N, Lynnerup O: Automatic Data Acquisition of Anthropological Measurements. Computers in Biology and Medicine 1993, 23:43-147.

24. Wilkinson L: SYSTAT Statistics. Systat Manual 1996.

25. Laitinen K, Välimäki M: Alcohol and Bone. Calcified Tissue International 1991, 49:70-73.

26. Schapira D: Alcohol Abuse and Osteoporosis. Seminars in Arthritis and Rheumatism 1990, 19:37I-376.

27. Preedy VR, Baldwin DR, Keating JW, Salisbury JR: Bone collagen, mineral and trace element composition, histomorphometry and urinary ydroxyproline excretion in chronically-treated alcohol-fed rats. Alcohol \& Alcoholism 1991, 26:39-46.

28. Laitinen K, Lamberg-Allardt C, Tunninen R, Karonen S, Ylikhari R, Välimäki M: Effects of 3 weeks' moderate alcohol intake on bone and mineral metabolism in normal men. Bone and Mineral 1991, 13:139-151.

29. Roche AF: Increase in cranial thickness during growth. Human Biology 1953, 25:81-92.

30. Hershkovitz I, Greenwald C, Rothschild BM, Latimer B, Dutour O, Jellema LM, Wish-Baratz S: Hyperostosis Frontalis Interna: An Anthropological Perspective. American Journal of Physical Anthropology 1991, 109:303-325.

31. Gurdjian ES, Webster JE, Lissner HR: The Mechanism of Skull Fracture. Radiology 1950, 54:313-339.

32. Bandak FA, Vander Vorst MJ, Stuhmiller LM, Mlakar PF, Chilton WE, Stuhmiller JH: An Imaging-based Computational and Experimental Study of Skull Fracture: Finite Element Model Development. Journal of Neurotrauma 1995, 12:679-688.

33. Krabbel G, Appel H: Development of a Finite Element Model of the Human Skull. Journal of Neurotrauma 1995, I 2:735-742.

\section{Publish with Bio Med Central and every} scientist can read your work free of charge

"BioMed Central will be the most significant development for disseminating the results of biomedical research in our lifetime. "

Sir Paul Nurse, Cancer Research UK

Your research papers will be:

- available free of charge to the entire biomedical community

- peer reviewed and published immediately upon acceptance

- cited in PubMed and archived on PubMed Central

- yours - you keep the copyright

Submit your manuscript here:

http://www.biomedcentral.com/info/publishing_adv.asp
BioMedcentral 